\title{
Modification of Drafting Zone of Jute Flyer Spinning Frame to Improve the Jute Yarn Quality
}

\author{
Md. Khalilur Rahman Khan, \\ Faculty of Engineering \& Applied Sciences, \\ Bangladesh University of Business and Technology, Dhaka. \\ Hosne Ara Begum, \\ Faculty of Textile Engineering, \\ Bangladesh University of Textiles, Dhaka
}

Doi:10.19044/esj.2020.v16n27p354 URL:http://dx.doi.org/10.19044/esj.2020.v16n27p354

\begin{abstract}
Being concerned with the growth and sustainability of the jute industry of Bangladesh, the machinery modifications deserves higher priority. In this work, it is desired to perform a modification of the apron draft spinning frame to improve the jute yarn quality. However, the existing drawing pressing roller (Diameter=70 mm \& Durometer hardness $=96$ in Shore A Scale) of the drafting zone of the apron draft jute spinning frame has been replaced by a comparatively softer rubber coated top roller (diameter $=40 \mathrm{~mm} \&$ Durometer hardness $=85$ in Shore A Scale). Besides, an extra slotted roller (Diamter= 26 mm \& Durometer hardness $=74$ in Shore A Scale) has also been nipped with bottom drawing roller and positioned parallel to the modified top roller. Three types of modifications have been designed by varying slot angles (i.e., $45^{\circ}$, $60^{\circ}$, and $75^{\circ}$ ) of slotted roller attached with the modified top roller. Finally, jute yarn counts of $6.5,8$, and $10 \mathrm{lbs} /$ spyndle have been produced for both existing and modified frames. Results reveal that the modified spinning frame with all three types of slotted roller produced better results regarding the yarn hairiness compared to the existing frame irrespective of yarn fineness. Yarn hairiness values in modified frame with $60^{\circ}$ slotted roller have been decreased maximum by $28.1 \%$, 35.85\%, and $32.92 \%$ compared to that of the existing system for 6.5, 8, and $10 \mathrm{lbs} /$ spyndle respectively. Yarn strength results have been improved with the modified system as well. Lastly, it is seen that ends down rate in modified spinning frames have been reduced noticeably irrespective of yarn fineness.
\end{abstract}

Keywords: Drafting Zone, Jute Spinning, Condensed Spinning, Yarn Hairiness 


\section{Introduction:}

Jute, the golden fiber, is the raw material of Bangladesh and Jute industries are the oldest sector of the economy from her very inception. Still, Bangladesh is the leading producer of jute and jute products as well. Hence, jute based production plays an influencing role in the countryes overall economy. However, this industry is continuing to function with significant drawbacks in terms of age-old machinery and technologies. In contrast to the cotton spinning industry that has received thorough going modifications since the mid-20th century, the Bangladesh jute industry has not positively responded to the needs of machinery modernization and technology upgradation. For the sake of the sustainability of jute spinning in Bangladesh, the modification of jute spinning machinery and processing improvements are the vital issue unquestionable.

Nowadays, in the jute sector, the demand for diversified jute products is growing profusely. In this regard production of jute yarn with improved quality is very much important for its diversified usages in the upcoming days of this industry. As a result, jute spinning should be preferred by researchers of Bangladesh for their field of study undoubtedly since jute is our prosperous raw materials. However, considering the above mentioned significant aspects of jute spinning it is desired in this experimental work to perform a modification of the apron draft spinning frame so that the quality of jute yarn can be improved.

Several researchers reported on various modifications of the drafting system of the ring spinning frame (Balasubramanian et al., 1995; Subodh et al., 2008; Tingting et al., 2011). Moreover, some researchers reported modifications of the drafting zone of the drawing frame in the jute spinning line (Mahabubuzzaman et al., 2011; Mohammad et al., 2011). Few researchers reported their work on the modifications of the jute flyer spinning frame (Miazi, 1997; Miazi et al., 2009; Mahabubuzzaman et al., 2003). However, the apron draft flyer type spinning machine is available in many jute mills in Bangladesh and other countries. There is no specific work based on the modification of the drafting zone of apron draft jute flyer spinning frame by applying the principle of the condensed spinning system. Hence, considering all the above excerpts, in this work, it is attempted to modify the elements of the drafting system of apron draft jute flyer spinning frame based on a mechanical condensed spinning principle to obtain better performances during the drafting and to entrap most of the fibers in the yarn body in the zone of the spinning triangle.

The objectives of this work are as follows: evaluating the performances of softer top roller in the drafting zone of jute spinning frame instead of (comparatively) harder drawing pressing roller of conventional frame, to analyze the possibility of integrating the concept of condensed spinning in jute 
spinning frame by using an extra slotted roller after passing the final nip point of drafting arrangement, to compare the existing frame and modified frame with respect to yarn quality parameters and productivity as well, to investigate the best-fitted slot angle of slotted roller used in the modified frame among the selected types of slot angle.

\section{Materials and Methods:}

\subsection{Modifications of Drafting System}

In the existing drafting system of the jute spinning frame, the Durometer hardness of the top drawing pressing roller was 96 in Shore A Scale. In this study, the drawing pressure roller (diameter $=70 \mathrm{~mm}$ ) of the jute spinning frame had been replaced by a cotton spinning type cot roller (diameter $=40 \mathrm{~mm}$ ). However, the nip point of synthetic rubber coated top roller was hanged by a distance of $5 \mathrm{~mm}$ with respect to the axis of the bottom drawing roller. An extra slotted roller had been positioned over the bottom drawing roller in parallel with the synthetic rubber coated top roller (shown in figure-1). Specifications rubber coated top roller is given in table-1. The design and real picture of the modified top roller are shown in Figures- 2 \& 3 respectively.

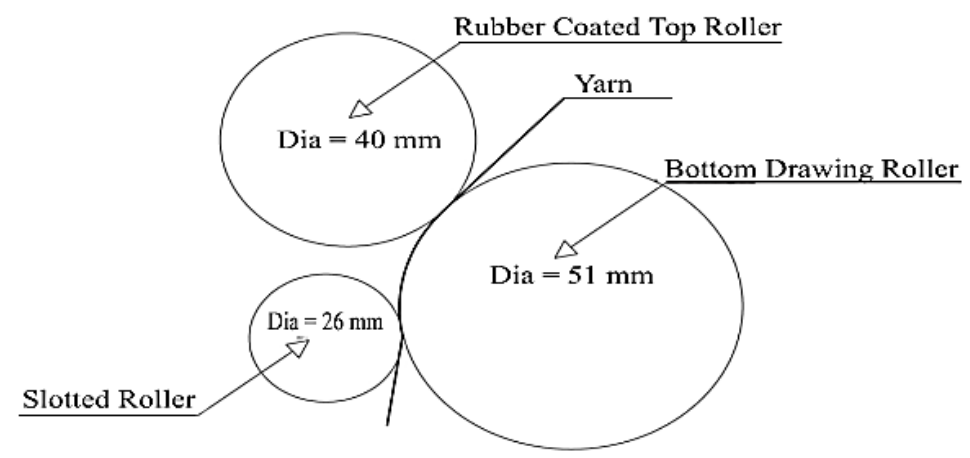

Figure-1: Arrangement of the modified top roller and slotted roller over bottom drawing roller.



Figure-2: Design of synthetic rubber coated top roller. 




Figure-3: Modified synthetic rubber coated top roller.

Table-1: Specifications of Rubber Coated Top Roller

\begin{tabular}{|c|c|c|}
\hline Sl No. & \multicolumn{2}{|c|}{ Specifications } \\
\hline 01. & Covering materials & $=$ Synthetic rubber \\
\hline 02. & Finished outer diameter & $=40 \mathrm{~mm}$ \\
\hline 03. & Bare roller diameter & $=10 \mathrm{~mm}$ \\
\hline 04. & Thickness of rubber coating & $=85$ in Shore A Scale \\
\hline 05. & $\begin{array}{c}\text { Durometer hardness of rubber } \\
\text { coatings }\end{array}$ & \\
\hline
\end{tabular}

The slots were symmetrically made up from two edges toward the roller center to provide a convergent path for the fibers in the strand at the spinning triangle. The slotted roller (specifications are given in table-2) had a multi-slot surface to lead fibers into the yarn end. To consider the effect of slot angle on yarn properties, slotted rollers of various slot angles had been designed and produced. In the figure- $4 \& 5$, the design and real picture of the slotted rollers are shown. The angle between the slot direction of the slotted roller and the centerline of drafted fiber strand was selected as $45^{\circ}, 60^{\circ}$, and $75^{\circ}$ for this experiment (e.g. angle between $45^{\circ}$ slotted roller and centerline of drafted fiber strand are shown in figure-6).



Figure-4: Design of Slotted Roller. 


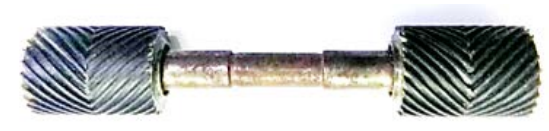

(i)

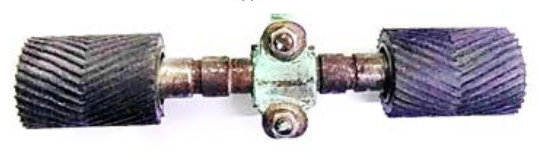

(ii)

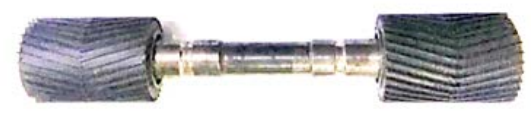

(iii)

Figure-5: Three types of slotted roller (i) $45^{\circ}$, (ii) $60^{\circ}$, and (iii) $75^{\circ}$

Table-2: Specifications of Slotted Roller.

\begin{tabular}{|c|c|c|}
\hline SI No. & \multicolumn{2}{|c|}{ Specifications of slotted roller } \\
\hline 01. & Covering materials & $=$ Nylon \\
\hline 02. & Finished outer diameter & $=26 \mathrm{~mm}$ \\
& Bare roller diameter & $=3 \mathrm{~mm}$ \\
\hline 03. & Thickness of nylon covering & $=1.5 \mathrm{~mm}$ \\
\hline 04. & Successive distance between slots & $=1.5 \mathrm{~mm}$ \\
\hline 05. & Depth of groove between successive slots & $=1 \mathrm{~mm}$ \\
\hline 06. & Thickness of each slot in slotted roller & a) $45^{\circ}$ \\
\hline 07. & Diagonal angle of the slots $60^{\circ}$ \\
c) $75^{\circ}$
\end{tabular}




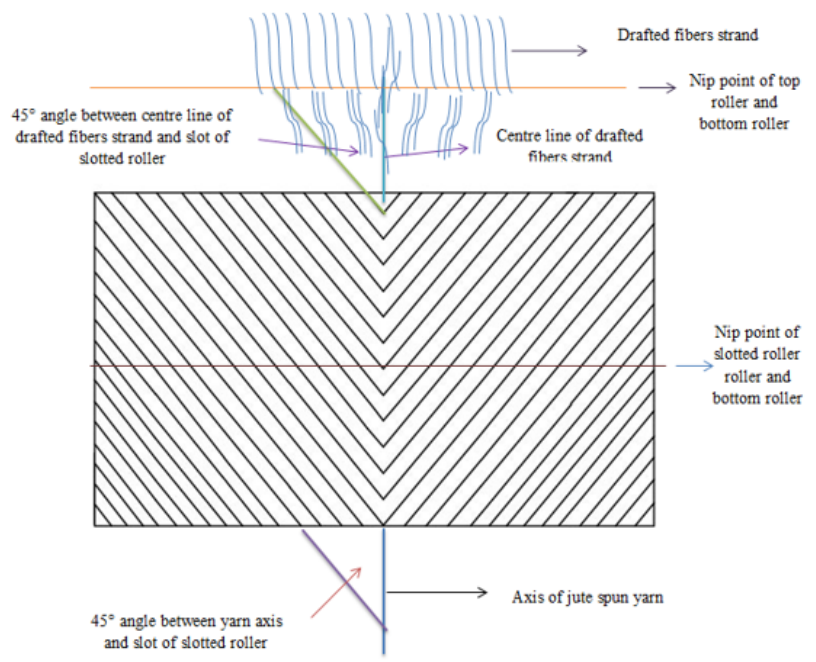

Figure-6: The angle between slot direction and the centerline of drafted fiber strand.

Also, the loading mechanism (pressure arm) in the existing drafting system (shown in figure-7) of the jute spinning frame was not exactly suitable for this work. For this reason, the pressure arm was changed somewhat (shown in figures-8) so that the modified top roller and slotted roller can be suspended and distanced from the pressure arm with using nut and bolt arrangement.

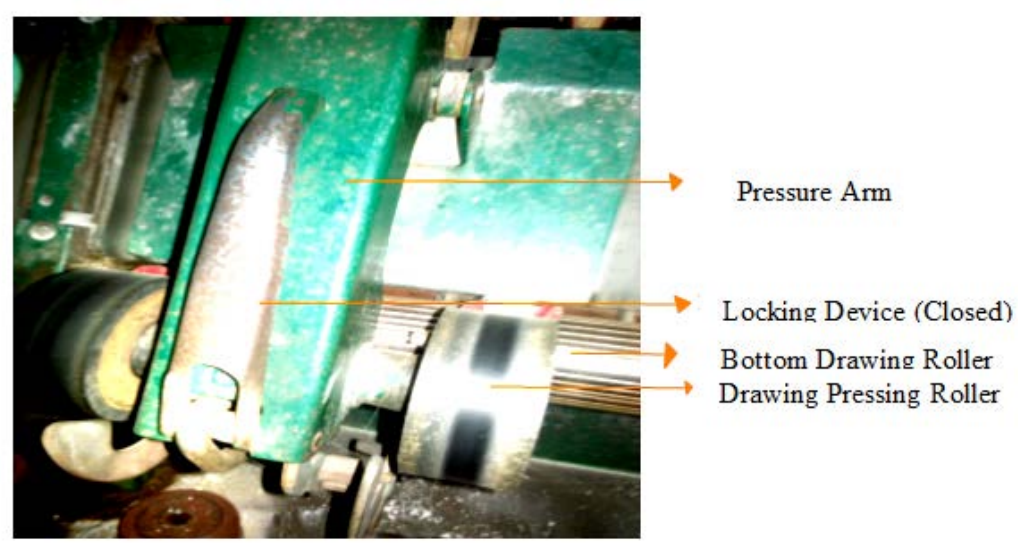

Figure-7: Top drawing pressure roller of the existing drafting system. 


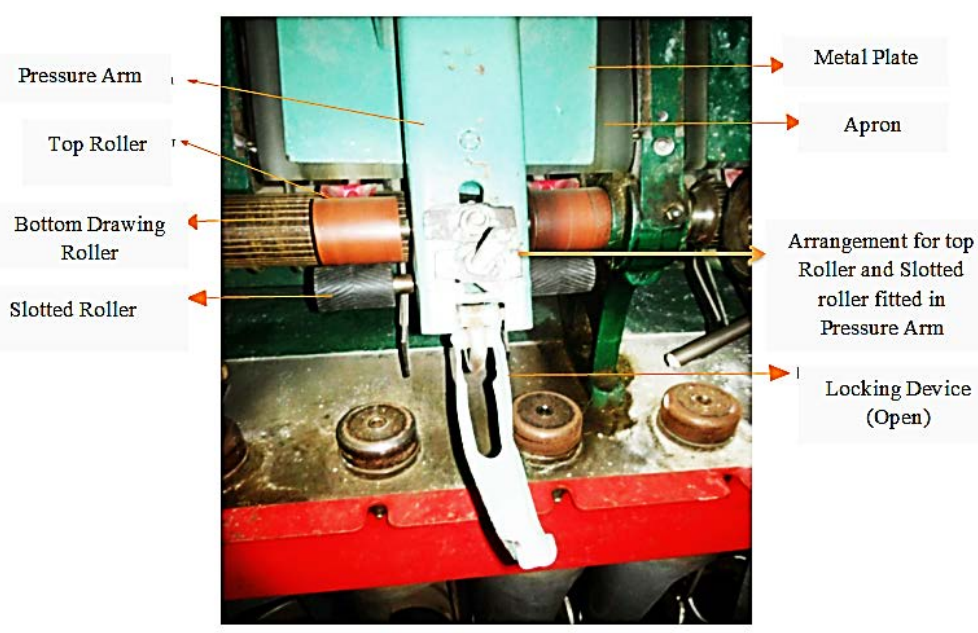

Figure-8: Pressure arm of the modified frame (Top roller loading system).

\subsection{Preparation of Yarn samples:}

However, Jute slivers were produced from white B Grade jute in the laboratory of the Bangladesh University of Textiles for this experiment. For producing jute sliver two cards (i.e., breaker card and finisher card) and three draw frames had been used and finally, slivers of 0.69 lbs per 100 yards were produced. Significant processing parameters such as moisture regain\% of breaker card sliver, finisher card sliver, and third drawn sliver were $17.49 \%$, $15.96 \%$, and $12.45 \%$ respectively. Average bundle fiber strength (g/Tex) was 30.60 for input slivers of the spinning frame. Moreover, the flyer rpm for this work was kept $3300 \mathrm{rpm}$ as always. The twist factor (k-factor) and draft constant were kept 12 and 750 respectively. The experimental workflow has been given in figure-9. For this work, it had been decided to produce yarn counts of $6.5 \mathrm{lbs} / \mathrm{spy}, 8 \mathrm{lbs} / \mathrm{spy}$, and $10 \mathrm{lbs} / \mathrm{spy}$ from the same jute sliver for each type of modification. As a result, total of twelve type samples of jute spun yarns were produced in this study. 




Figure-9: Experimental workflow.

\subsection{Testing Procedure:}

Moisture regain\% of different types of slivers were measured by the direct method (i.e., Oven dry method) whereas bundle fiber strength values were measured by Stelometer. It is worth mentioning that the hardness of the top roller and slotted roller were measured by the durometer in Shore A Scale. However, jute yarn fineness had been determined by the wrap reel and electric balance method. Jute yarn hairiness values were tested on Premier evenness tester and jute yarns tensile strength results were measured by Titan strength tester (ASTM D2256). Lastly, the yarn breakage rate was calculated for each sample by observing the total numbers of piecing required per hour per spindle during yarn production.

Table-3. Experimental Results

\begin{tabular}{|c|c|c|c|c|c|}
\hline \multirow[t]{3}{*}{ Particulars } & \multirow{3}{*}{$\begin{array}{c}\text { Count } \\
\text { (lbs/spy) }\end{array}$} & \multicolumn{4}{|c|}{ Independent Variables } \\
\hline & & Type-A & Type-B & Type-C & Type-D \\
\hline & & Existing Frame & $\begin{array}{c}\text { Modified } \\
\text { With } 45^{\circ} \\
\text { slotted roller }\end{array}$ & $\begin{array}{c}\text { Modified } \\
\text { With } 60^{\circ} \\
\text { slotted roller }\end{array}$ & $\begin{array}{c}\text { Modified } \\
\text { With } 75^{\circ} \\
\text { slotted roller }\end{array}$ \\
\hline \multirow{3}{*}{$\begin{array}{c}\text { Yarn } \\
\text { hairiness } \\
\text { (Hairiness } \\
\text { Index) }\end{array}$} & $\begin{array}{c}6.5 \\
\text { (lb/spy) }\end{array}$ & 7.37 & 6.69 & 5.30 & 5.85 \\
\hline & 8 (lb/spy) & 8.62 & 7.14 & 5.53 & 5.94 \\
\hline & $\begin{array}{c}10 \\
\text { (lb/spy) }\end{array}$ & 7.14 & 6.26 & 4.79 & 4.9 \\
\hline \multirow{2}{*}{$\begin{array}{c}\text { Yarn Tensile } \\
\text { Strength } \\
\text { (cN/Tex) }\end{array}$} & $\begin{array}{c}6.5 \\
\text { (lb/spy) }\end{array}$ & 11.74 & 11.28 & 12.38 & 12.24 \\
\hline & 8 (lb/spy) & 12.7 & 13.88 & 14.01 & 13.68 \\
\hline
\end{tabular}




\begin{tabular}{|c|c|c|c|c|c|}
\hline & $\begin{array}{c}10 \\
\text { (lb/spy) }\end{array}$ & 13.04 & 13.97 & 14.31 & 14.81 \\
\hline \multirow{3}{*}{$\begin{array}{c}\text { Ends } \\
\text { Down/spindl } \\
\text { e/hour }\end{array}$} & $\begin{array}{c}6.5 \\
\text { (lb/spy) }\end{array}$ & 23 & 18 & 18 & 19 \\
\hline & 8 (lb/spy) & 16 & 12 & 11 & 13 \\
\hline & $\begin{array}{c}10 \\
\text { (lb/spy) }\end{array}$ & 14 & 13 & 9 & 11 \\
\hline
\end{tabular}

\section{Results and Discussion:}

\section{i) Yarn Hairiness:}

Jute yarn hairiness significantly influences the properties of jute yarns and fabrics. However, it is seen (shown in table-3) that each type of modification of the drafting zone performed in this work has positively influenced the yarn hairiness value irrespective of jute yarn fineness. Yarn hairiness values for $6.5 \mathrm{lbs} /$ spyndle, $8 \mathrm{lbs} /$ spyndle, and $10 \mathrm{lb} / \mathrm{spyndle}$ have been reduced up to $28.1 \%, 35.8 \%$ and $32.9 \%$ respectively with the modified drafting system of jute spinning frame. Among the three types of slotted rollers, modification with $60^{\circ}$ slotted roller gives minimum hairiness values for all three jute yarn counts without any exception (shown in figure-10). The hairiness values of jute spun yarn obtained by Type-C are approximately $71.91 \%, 64.15 \%$, and $67.08 \%$ of the results of the existing frame for three yarn counts (i.e., 6.5, 8, and $10 \mathrm{lbs} / \mathrm{spy}$ ) respectively. This improvement in hairiness results for the modified drafting system may be explained in such a way that the spinning triangle of the modified drafting system will create lower width that gives lower hairiness value in general. In the existing spinning frame, the fiber strand coming from the nip point of the drawing roller and drawing pressing roller is flat and almost all fibers are parallel to the axis of the fiber strand. But in the modified drafting zone, the width of the fiber strand begins to reduce gradually from the nip point of rubber-coated top roller to the nip point of the slotted roller. Ultimately yarn hairiness for all samples of the modified drafting zone has been reduced. It also may be due to the small grooves of a slotted roller divide the drafted strand into multi-strands. These multi strands are finally twisted after passing the nip point of the slotted roller. It is implicated that this multi-strands phenomenon resulting in the reduction of yarn hairiness due to the dividing effects performed by the slotted roller. More of the fiber ends appear to be trapped by the "yarn-formation trapping mode”, resulting in a reduction in yarn hairiness. 


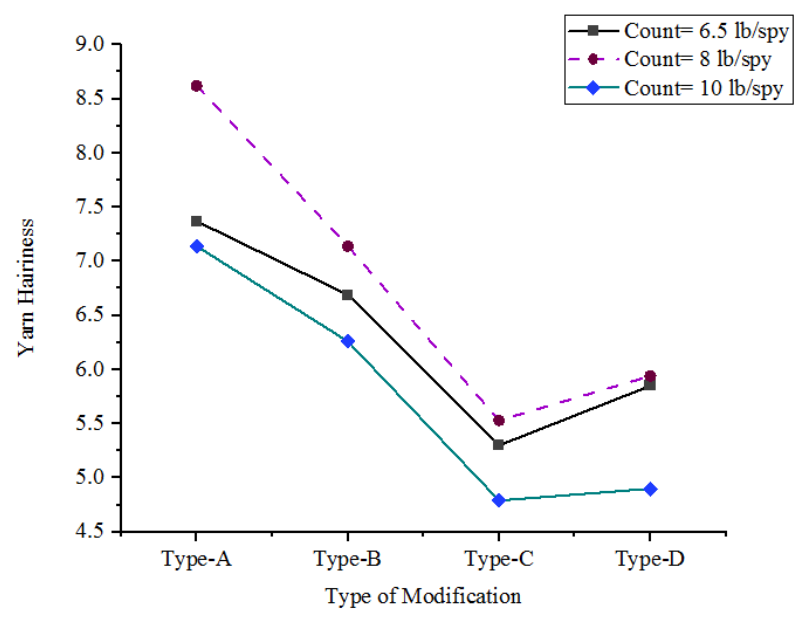

Figure-10. Graphical representation of yarn hairiness results.

\section{ii) Yarn Strength:}

The tensile strength of a yarn is important to the processability of the yarn in the downstream processing and operational life of the substrate made with the yarn. However, from the results of single jute yarn tensile strength (shown in table-3), it is significantly seen that the results of yarn tensile strength have been increased for $8 \mathrm{lbs} /$ spyndle and $10 \mathrm{lbs} /$ spyndle with all three types of modifications in comparison with the existing drafting system. In the case of $6.5 \mathrm{lbs} / \mathrm{spyndle,} \mathrm{it} \mathrm{is} \mathrm{worth} \mathrm{notable} \mathrm{that} \mathrm{tensile} \mathrm{strength}$ results have been increased for modified drafting system with $60^{\circ}$ and $75^{\circ}$ slotted rollers whereas $45^{\circ}$ slotted roller slightly deteriorates yarn tensile strength compared to jute yarn produced in the existing frame (shown in figure-11). In the case of $10 \mathrm{lbs} /$ spyndle, the yarn breaking force (cN/Tex) for the modified system with $45^{\circ}, 60^{\circ} \& 75^{\circ}$ slotted roller have been increased by approximately $7.13 \%, 9.74 \% \& 13.57 \%$ respectively. In the case of 8 lbs/spyndle, the yarn breaking forces for the modified system with $45^{\circ}, 60^{\circ} \&$ $75^{\circ}$ slotted roller have been increased by approximately $9.3 \%, 10.3 \% \& 7.7 \%$ respectively. However, these improvements in strength results may be occurred due to a reduction in the distance between the final roller nip point and twisting position, resulted in a better twist backpropagation. As a result, better twist flow to the spinning triangle leads to better locking of fibers. Ultimately, yarn tensile strengths have been increased in general. On the other hand, yarn hairiness results (in figure-10) show that jute yarn produced from the modified drafting systems have lower levels of hairiness. So, it can be said that the hair fibers have been locked in the yarn body, resulting in a better contribution to yarn tensile strength as well. 


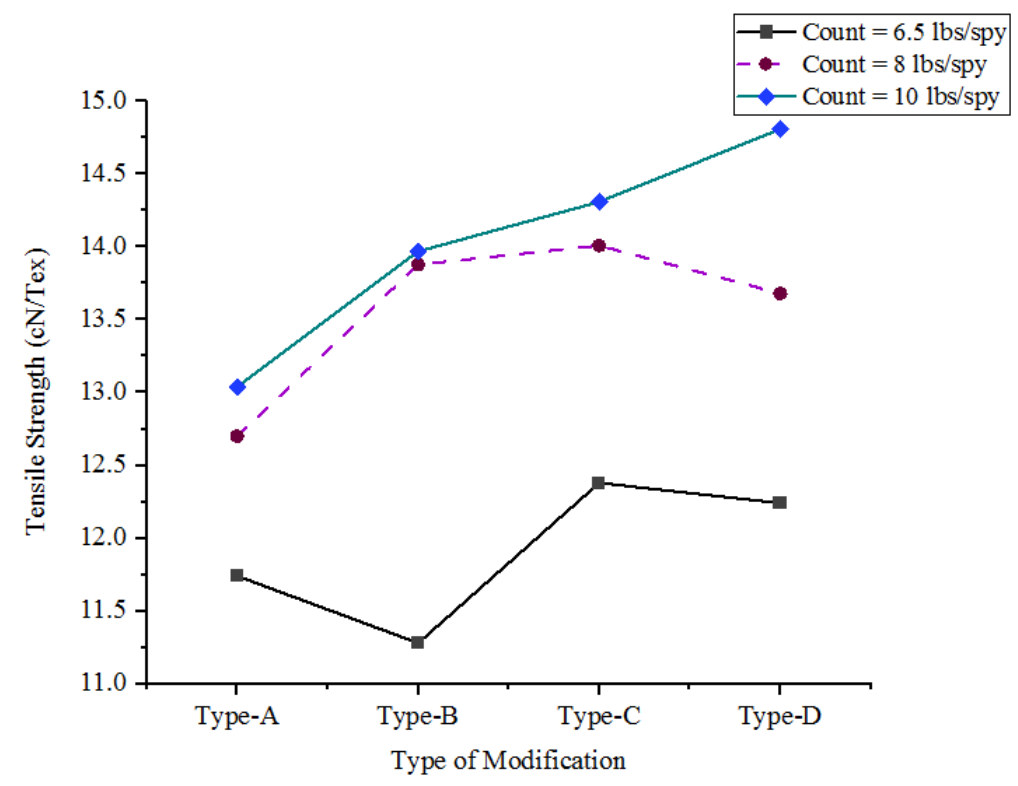

Figure-11. Jute single yarn tensile strength (cN/Tex) results.

\section{iii) Yarn Breakage:}

One basic way to increase the profit and quality in the spinning process is to keep the end breakage rate to a minimum level. The end breakage is a critical spinning parameter that not only affects the maximum spindle speed but may also indicate the quality of yarn. However, It is worth mentioning that the breakage results of jute spun yarns produced by the modified drafting system have decreased compared to the existing drafting zone irrespective of yarn linear density (shown in figure-12). The trend of the results found for the modified frame may be happened due to lowering the final nip point of fibers by using an extra overhang slotted roller after the nip point of the rubber-coated top roller. Since the final nip point for fibers has been lowered, so the length of the spinning triangle would be decreased. The short spinning triangle will give lower yarn breakage compared to a long spinning triangle in general. However, this may be also explained in such a way that using an extra slotted roller may increase the locking process of the fibers by better guidance of fibers during twisting that resulted in the reduction of yarn breakage also. 




Figure-12. Results of yarn Ends Down Rate/ sp./Hr.

\section{Summary of Findings:}

The following results are interestingly obtained in this work:

i) With reference to yarn hairiness, a dramatic result is seen in the experimental results of this study with all three types of modified spinning frames without any exception. However, spinning frame modified with $60^{\circ}$ slotted roller gives best result in term of yarn hairiness irrespective of yarn fineness. Spinning frame modified with $60^{\circ}$ slotted roller has decreased yarn hairiness by $28.09 \%$, 35.85\% \& 32.92\% for yarn counts of 6.5, 8 \& $10 \mathrm{lbs} /$ spyndle respectively compared to the jute yarn hairiness of the existing frame.

ii) Regarding the single jute yarn strength value (cN/tex), modification with $45^{\circ}, 60^{\circ} \& 75^{\circ}$ Slotted roller have increased yarn strength by $7.13 \%, 9.74 \%$ \& $13.57 \%$ respectively for 10 lbs/spy and $9.3 \%, 10.3 \% \& 7.7 \%$ respectively for $8 \mathrm{lbs} /$ spyndle compared to the existing frame. It is worth mentioning that spinning frame modified with $60^{\circ} \& 75^{\circ}$ slotted roller have increased yarn strength compared to existing frame during 6.5 $\mathrm{lbs} /$ spyndle yarn production. Spinning frame modified with $45^{\circ}$ slotted roller has decreased jute yarn strength somewhat exceptionally for $6.5 \mathrm{lb} / \mathrm{spy}$.

iii) Yarn breakage rate have been reduced with all types of modified spinning frames of this study compared to the existing frame without any exception. However, Jute flyer spinning frame modified with $60^{\circ}$ slotted roller reduce yarn breakage by $21.7 \%$, 31.2\% \& 35.7\% for $6.5 \mathrm{lbs} / \mathrm{spy}, 8 \mathrm{lbs} / \mathrm{spy}$ \& $10 \mathrm{lbs} /$ spy respectively. 


\section{Conclusion:}

The presented work demonstrated the effects of modified drafting zone on the quality parameters of jute spun yarn such as yarn strength, hairiness and also on the end breakage rate of the jute flyer spinning frame. However, keeping all other parameters same, when drawing pressing roller of jute spinning frame had been replaced by a comparatively softer type rubber coated top roller and with an extra slotted roller that has been nipped with bottom drawing roller and positioned parallel to top roller, then it is seen that jute yarn quality paramaters such as yarn hairiness, strength have been improved significantly compared to the existing jute flyer spinning frame. Besides, the yarn ends down rate for jute yarn have also been decreased distinguishably during jute production in the modified spinning frame. As a result, productivity of jute spun yarn will be increased with modified spinning frame as well. By comparing all obtained results, it can be concluded that modification of drafting zone with $60^{\circ}$ slotted roller of jute spinning frame give best results in general. Finally, it can be summed up that modification effort given in this work is more suitable for producing jute yarn with improved quality. Ultimately, this type of improvement in jute yarn quality will create opportunity of using jute yarn in many applications where appearance, surface smoothness etc. are matter of concern. Lastly, experimental investigations in this work have been performed by modifying only one head of drafting zone of jute spinning frame that can be considered as a significant limitation of this study. Further research can be done on investigating the effects of the pneumatic condensing system added in jute flyer spinning frame during yarn formation.

\section{References:}

1. NB Balasubramanian, R Krishnaswamy \& Jyotsna Sharma, (1995), Modifications to drafting system for improvement in yarn quality, Indian Journal of Fiber \& Textile Research, Vol. 20, December 1995, PP. 169-175.

http://nopr.niscair.res.in/bitstream/123456789/32318/1/IJFTR\%2020 \%284\%29\%20169-175.pdf

2. Subodh J. Dudheria, Sandeep R. Balar, (2008), Ring Spinning Technology: Development in Drafting System Published: Nov 2008, https://www.fibre2fashion.com/industry-article/3734/ring-spinningtechnology-development-in-drafting-system

3. Tingting Wua , Chunping Xiea, Xuzhong Sua,, Xinjin Liua,, Bin Huanga, (2011), A Modified Ring Spinning System with Various Diagonal Yarn Path Offsets, Procedia Engineering 18 (2011) 1 - 6. https://www.sciencedirect.com/science/article/pii/S18777058110280 37 
4. A.K.M. Mahabubuzzaman , Md. Osman Ghani Miazi, Mohammad Abdul Jalil and Rabindra Chandra Sinha , (2011), Enrichment of yarn quality by the change of drafting zone of drawing machines, Daffodil International University Journal of Science and Technology, Vol. 6, Issue 1, January 2011.

5. Mohammad Abdul Jalil, Rabindra Chandra Sinha, A.K.M Mahabubuzzaman, MD. Rokonuzzaman,(2011), A comparative study on the quality control of fine jute yarn conventional drawing method vs modified drawing method, International Journal of Textile and Fashion Technology (IJTFT), Vol.1, Issue 1 (2011) 1-10.

6. Md. Osman Ghani Miazi, (1997), Adapt an on of ring spinning in the flyer spinning machine for making fine jute yarn, BUET, Dhaka, Bangladesh. September, 1997.

7. M. Osman Ghani Miazi, A.K.M. Mahabubuzzaman, Mohammad Maniruzzaman, Mohammad abdul Jalil and M. Abdus Shahid, (2009), Effect of twist on productivity of fine jute yarn produced by modified ring spinning machine, j. innov.dev.strategy. 3(4): August 2009.

8. A.K.M. Mahabubuzzaman, Latifa Binte Lutfar, Md. Asaduzzaman, Md. Osman Gani Miazi , F.A. Dilruba and Zakaria Ahmed, (2003), Study on the Quality of Gardella Fine Yarn in Comparison to Modified Ring Spinning Frame Fine Yarn, Pakistan Journal of Biological Sciences, Volume 6 (1): 76-77, 2003. 